\title{
Associations of cardiorespiratory fitness with cardiovascular disease risk factors in middle-aged Chinese women: a cross-sectional study
}

\author{
Wenfei $\mathrm{Zhu}^{1+}$, Steven P Hooker ${ }^{1+}$, Yuliang Sun ${ }^{2+}$, Minhao Xie $^{3+}, \mathrm{Hao} \mathrm{Su^{3+ }}$ and Jianmin $\mathrm{Cao}^{4^{*}}$
}

\begin{abstract}
Background: High levels of physical activity (PA) and cardiorespiratory fitness (CRF) are each associated with a favorable cardiovascular disease (CVD) risk profile. However, the relationship between CRF and obesity is still inconsistent across studies, and there has been no thorough exploration of the independent contribution of CRF to different CVD risk factors in Chinese women. This study investigated the relationship between CRF and CVD risk factors in 40-49 year old women in Beijing.

Methods: The study included 231 urban-dwelling asymptomatic 40-49 year old women. Body mass index (BMI), body fat percentage (BF\%), blood glucose, blood lipids, blood pressure, and pulse wave velocity (PWV) were measured at rest. Cycle ergometer exercise tests were conducted to assess CRF as indicated by maximal oxygen uptake $\left(\mathrm{VO}_{2 \mathrm{max}}\right)$. Participants were categorized into three CRF levels (low, moderate and high).

Results: High CRF level was associated with significantly less BF\%, lower PWV, and higher weekly physical activity compared with low and moderate CRF $(P<0.05)$. Compared to high CRF, the odds ratios for having $\geq 3$ main CVD risk factors (overweight, hypertension, and dyslipidemia) in low and moderate CRF were 2.09 (95\% Cl: 1.48-2.94) and 1.84 (95\% Cl: 1.29-2.62), respectively. The proportion of participants with clinical ST segment depression and prolonged QTC interval during cycle ergometer testing was significantly higher in women with low CRF.

Conclusions: Overall, Chinese middle-aged women demonstrated a moderate level of CRF. CRF was independently associated with CVD risk factors, including overweight, hypertension, dyslipidemia, arterial stiffness, and abnormal ECG during exercise, with the least fit women exhibiting the highest number of CVD risk factors.
\end{abstract}

\section{Background}

With China's rapid economic development, cardiovascular disease (CVD) has become the leading cause of death among Chinese adults [1]. Among Chinese women, the five leading causes of death are diseases of the heart, cerebrovascular disease, malignant neoplasms, pneumonia/influenza, and infectious diseases [1]. Physical inactivity and CVD risk factors such as obesity, hypertension, and dyslipidemia, are significantly related to the all-cause mortality in China [1]. Research suggests control of CVD risk factors and increased physical activity (PA) are two important strategies for reducing the burden of premature

\footnotetext{
* Correspondence: bsujianmincao@yahoo.com

${ }^{\dagger}$ Equal contributors

${ }^{4}$ Sport Biochemistry Program, Sport Science College, Beijing Sport University, No.48 Xinxi Road, Beijing, Haidian District 100084, P. R. China

Full list of author information is available at the end of the article
}

death among Chinese adults [1-3]. There is strong and consistent evidence indicating PA and cardiorespiratory fitness (CRF) independently predict the risk of CVD [4]. As an objective measurement of PA, CRF plays an important role in the relationship between PA and CVD, and could avoid the limitation of some studies in which PA was self-reported and participative. Recent studies [5,6] have demonstrated higher levels of CRF are associated with a favorable CVD risk profile, while women with lower CRF have an increased prevalence of CVD. Thus, effective improvement in PA and CRF may have significant implications for the clinical and public health burden of CVD [7-10].

To our knowledge, although a small number of previous studies have explored the relationship between self-reported PA and CVD $[3,11]$, the association between CRF and CVD risk factors in Chinese middle-aged women 
has not been reported. Also, the relationship of CRF with fatness, arterial stiffness and abnormal ECG during exercise testing is still unclear. Therefore, the purpose of this study was to investigate the relationship between objectively measured CRF and the CVD risk factor profile, including overweight, hypertension, dyslipidemia, arterial stiffness, and abnormal ECG during exercise, in Chinese middle-age women.

\section{Methods}

\section{Participants}

The current study was conducted at Beijing Sport University from May to December in 2010. Four hundred and sixtynine women 40-49 years of age living in the urban area of Beijing participated in a larger CVD surveillance study and completed an extensive questionnaire. Personal information included social background (age, sex, family income, and education), smoking, alcohol consumption, food frequency, previous disease history and family history. PA was assessed with the long Chinese version of the International Physical Activity Questionnaire (IPAQ) [12]. The IPAQ assesses PA undertaken for seven consecutive days across a comprehensive set of domains including leisure time PA, household and gardening (yard) activities, work-related PA, and transport-related PA. Computation of the total score requires summation of the duration (in minutes) and frequency (days) for all the types of activities in all domains. The final unit of PA is expressed as MET $\cdot$ minutes $\cdot$ week $^{-1}$.

Two hundred and thirty-one women (age: $44.5 \pm 3.3 \mathrm{yr}$, BMI: $23.8 \pm 3.5 \mathrm{~kg} \cdot \mathrm{m}^{-2}$ ) voluntarily agreed to undertake additional laboratory tests. Test contents and requirements were confirmed with all participants by telephone two days prior to visiting the lab. Each participant was free of any exercise testing contraindications [13]. The study was approved by the Ethical Committee of Beijing Sport University. The nature, benefits, and risks of the study were explained to prospective participants and written informed consent was obtained before involvement in the study.

\section{CVD risk factors measurement}

Height and weight were measured by standardized procedures [13]. Body mass index (BMI) was calculated as weight divided by height squared $\left(\mathrm{kg} \cdot \mathrm{m}^{-2}\right)$. Waist circumferences (WC) were assessed at the thinnest position between the lowest rib and iliac crest [13]. Standard bioelectrical impedance analysis (BIA) assessments (Biospace Inbody 3.0) were performed with electrodes placed at the upper and lower extremities to determine body fat percentage (BF\%).

Systolic blood pressure (SBP) and diastolic blood pressure (DBP) were measured with a Digital Blood Pressure Monitor (BIOspaceTM-2655/P) with participants in the upright-seated position. Participants rested for at least 5 minutes before the measurements. A minimum of 2 readings were obtained at intervals of at least 1 minute, with the average of those used to represent the participants' blood pressure. If there was more than $5 \mathrm{~mm} \mathrm{Hg}$ difference between the first and second reading, additional ( 1 or 2 ) readings were obtained, with the average of these multiple readings used.

Biochemistry measurements were assessed at 8:00 am on the test day following a 12-hour fast. Fasting blood glucose (FBG) was assessed by Roche Blood Glucose Meter (ACCU-CHEK Active). Triglyceride (TG) and total cholesterol (TC) were assessed by endpoint method [13]. High-density lipoprotein cholesterol (HDL-C) and lowdensity lipoprotein cholesterol (LDL-C) were measured by direct testing method [13]. For tests of TG, TC, HDL-C and LDL-C, kit products manufactured by Beijing Leadman Biochemistry Co., Ltd. were used, with a Hitachi 7020 automatic biochemical analyzer utilized to attain final data for analysis.

Brachial-ankle pulse wave velocity (PWV) and Ankle Brachial Index (ABI) were measured in a quiet temperaturecontrolled room. A volume-plethysmograph(OMRON BP-203RPE) was employed to record PWV, ABI, BP, electrocardiogram (ECG), and heart sounds simultaneously. Participants were examined in the supine position, with ECG electrodes on both wrists, a microphone for detecting heart sounds on the left edge of the sternum, and cuffs wrapped on both the brachia and ankles. Cuffs were connected to a plethysmographic sensor to determine volume pulse form and an oscillometric pressure sensor to measure BP. Pulse wave for the brachium and ankle were stored, and sampling time was 10 seconds with automatic gain analysis and quality adjustment. After instrumentation, participants rested in the supine position for at least 10 minutes before data collection.

We used CVD risk factor thresholds according to American College of Sport Medicine (ACSM) to evaluate the CVD risk [13].

\section{Exercise test}

During interviews, we learned that most participants had no or few experiences of exercise training on treadmills. However, they were very familiar with bicycle riding with a large majority of the women using a bicycle for daily commuting. Therefore, we conducted incremental cycle ergometer tests on an electronically braked ergometer (Merits Custo Med EC3000) to measure CRF. Participants were instructed abstain from any strenuous exercise on the day before testing. Maximal oxygen uptake $\left(\mathrm{VO}_{2 \max }\right)$ was measured directly by collecting breathing gas with a mask. A gas analyzer (Cortex Metalyzer), which was validated in a previous study [14], recorded and computed the gas exchange. The analyzer was calibrated 
before each test. The initial workload was $0 \mathrm{~W}$ for one minute and increased $25 \mathrm{~W}$ every 2 minutes until the participant was exhausted or not able to maintain the required pedaling rate of $60 \mathrm{rpm}$ [7]. During the test, ECG (Custo Med 12 guide Holter monitor) and BP (Suntec Tango ${ }^{+}$ monitor) were recorded. ST segment changes and corrected QT (QTC) interval were also recorded. The criteria for myocardial ischemia in ECG was horizontal or downsloping ST segment depression $\geq 1.0 \mathrm{~mm}$ at $80 \mathrm{msec}$ after J point [13]. Abnormal QTC interval was considered as an affiliated measure of myocardial ischemia in addition to ST segment depression. The criteria for abnormal QTC interval was QTC interval $<470 \mathrm{msec}$ [13]. Rated Perceived Exertion (RPE) (Scale: 6-20) was used to test subjective feelings of fatigue and recorded 10 seconds before the end of each workload. The test was terminated when the participant reached peak $\mathrm{VO}_{2 \max }$ [13] or showed any symptoms contraindicating continuation of exercise according to ACSM guidelines [13]. Based on previous researches $[4,15]$, participants were categorized into three CRF groups (low, moderate and high). The least fit $20 \%$ were classified as low fit, the next higher $40 \%$ as moderately fit, and the top $40 \%$ as high fit.

\section{Data analysis}

Differences in CVD risk factors related to overweight, hypertension, and dyslipidemia among the three CRF levels were examined by one-way ANOVA. Tukey posthoc tests were used to test for differences between groups. Differences in proportions of participants with CVD risk factors were examined by chi-square analysis. Logistic regression tested the association between CRF levels and the number of CVD risk factors (overweight, hypertension, and dyslipidemia) with adjustment for age, family history, income, education, smoking, diet, alcohol consumption and total weekly PA. Differences of odds ratios of ST segment depression and long QTC interval during the cycle exercise test were also examined by logistic regression after adjustment of the covariates mentioned above and all other CVD risk factors. Repeated measure analysis was used to examine the trend of change in the ST segment and QTC interval during cycle exercise test. Data were analyzed with SPSS for Windows (version 21.0). $P<0.05$ denoted statistical significance.

\section{Results}

Demographic characteristics and CVD risk factors are displayed in Tables 1 and 2. The mean $\mathrm{VO}_{2 \max }$ was $27.35 \pm 5.53 \mathrm{ml} \cdot \mathrm{kg}^{-1} \mathrm{~min}^{-1}$, which was at a moderate level for the population's gender and age [13]. The average total weekly PA was $3476.29 \pm 3771.36 \mathrm{MET} \cdot \mathrm{min} \cdot$ week $^{-1}$, which was at the high level of PA according to the IPAQ scoring protocol (high level: total PA >3000 MET-minutes/week). A majority (72.3\%) of total weekly

Table 1 Characteristics of participants

\begin{tabular}{|c|c|c|c|c|c|c|c|c|}
\hline \multirow[t]{3}{*}{ Variable } & \multicolumn{8}{|c|}{ Fitness level $^{a}$} \\
\hline & \multicolumn{2}{|c|}{ Low $(N=47)$} & \multicolumn{2}{|c|}{ Moderate $(\mathrm{N}=92)$} & \multicolumn{2}{|c|}{ High $(\mathrm{N}=92)$} & \multicolumn{2}{|c|}{ Total $(\mathrm{N}=231)$} \\
\hline & Mean & SD & Mean & SD & Mean & SD & Mean & SD \\
\hline Age (year) & 44.05 & 3.27 & 44.93 & 3.28 & 45.08 & 3.09 & 44.53 & 3.27 \\
\hline Body Mass Index $\left(\mathrm{kg} \cdot \mathrm{m}^{-2}\right)$ & 24.24 & 3.60 & 23.62 & 3.54 & 22.90 & 2.64 & 23.81 & 3.48 \\
\hline Waist Circumference (cm) & 82.69 & 9.71 & 81.05 & 9.45 & 80.49 & 8.04 & 81.75 & 9.40 \\
\hline Body Fat (\%) & 32.07 & 6.11 & 28.75 & $5.25^{\mathbf{b}}$ & 28.05 & $5.62^{d}$ & 30.21 & 5.96 \\
\hline Fasting Glucose $\left(\mathrm{mmol} \cdot \mathrm{L}^{-1}\right)$ & 5.44 & 1.13 & 5.52 & 0.85 & 5.56 & 1.62 & 5.49 & 1.10 \\
\hline Total Cholesterol $\left(\mathrm{mg} \cdot \mathrm{dl}^{-1}\right)$ & 168.84 & 137.98 & 139.59 & 127.26 & 149.95 & 87.21 & 157.40 & 130.07 \\
\hline HDL-Cholesterol $\left(\mathrm{mg} \cdot \mathrm{dl}^{-1}\right)$ & 52.78 & 10.30 & 57.90 & 12.97 & 50.53 & 9.90 & 54.29 & 11.40 \\
\hline LDL-Cholesterol $\left(\mathrm{mg} \cdot \mathrm{dl}^{-1}\right)$ & 127.33 & 116.94 & 97.55 & 44.01 & 113.60 & 27.10 & 116.17 & 93.22 \\
\hline Systolic BP $(\mathrm{mmHg})$ & 115.01 & 13.47 & 114.82 & 14.81 & 117.41 & 14.47 & 115.25 & 14.07 \\
\hline Diastolic BP ${ }^{\mathrm{e}}(\mathrm{mmHg})$ & 74.00 & 9.54 & 74.45 & 9.70 & 75.82 & 12.61 & 74.41 & 10.00 \\
\hline Total PA ${ }^{\mathrm{e}}\left(\mathrm{MET} \cdot \mathrm{min} \cdot\right.$ week $\left.^{-1}\right)$ & 3058.6 & 2782.8 & 3368.7 & 3290.9 & 5273.9 & $6737.7^{\mathbf{d}}$ & 3476.2 & 3771.3 \\
\hline Total sitting time $\left(\min \cdot\right.$ week $\left.^{-1}\right)$ & 1824.8 & 959.8 & 2020.5 & 990.6 & 2003.7 & 1077.5 & 1925.8 & 987.1 \\
\hline Pulse Wave Velocity $\left(\mathrm{cm} \cdot \mathrm{s}^{-1}\right)$ & 1345.21 & 182.70 & 1272.92 & 158.44 & 1220.64 & $168.36^{\mathbf{d}}$ & 1262.17 & 169.74 \\
\hline Ankle Brachial Index & 1.13 & 0.08 & 1.15 & 0.10 & 1.15 & 0.09 & 1.14 & 0.09 \\
\hline $\mathrm{VO}_{2 \mathrm{MAX}}{ }^{\mathrm{e}}\left(\mathrm{mL} \cdot \mathrm{min}^{-1} \cdot \mathrm{kg}^{-1}\right)$ & 22.95 & 3.28 & 29.56 & $1.43^{\mathbf{b}, \mathbf{c}}$ & 36.37 & $4.60^{d}$ & 27.35 & 5.53 \\
\hline
\end{tabular}

${ }^{\mathrm{a} A c c o r d i n g}$ to $\mathrm{Vo}_{2 \max }$, the least fit $20 \%$ were classified as low fit, the next $40 \%$ as moderately fit, and the top $40 \%$ as high fit.

benotes significant difference $(P<0.05)$ between moderate and low CRF groups.

'Denotes significant differences $(P<0.05)$ between moderate and high CRF groups.

${ }^{\mathrm{d} D e n o t e s}$ significant difference $(P<0.05)$ between high and low CRF groups.

${ }^{\mathbf{e}} \mathrm{BP}$ refers to blood pressure, $\mathrm{PA}$ refers to physical activity, $\mathrm{Vo}_{2 \max }$ refers to maximal oxygen uptake during exercise testing. 
Table 2 Proportion of cardiovascular disease risk factors in low, moderate and high cardiorespiratory fitness groups

\begin{tabular}{|c|c|c|c|c|c|c|c|c|}
\hline \multirow[t]{3}{*}{ Variable $^{a}$} & \multicolumn{8}{|c|}{ Fitness level $^{\mathbf{b}}$} \\
\hline & \multirow{2}{*}{\multicolumn{2}{|c|}{$\begin{array}{c}\text { Low }(\mathrm{N}=47) \\
N(\%)^{c}\end{array}$}} & \multirow{2}{*}{\multicolumn{2}{|c|}{$\begin{array}{c}\text { Moderate }(\mathrm{N}=92) \\
\mathrm{N}(\%)\end{array}$}} & \multirow{2}{*}{\multicolumn{2}{|c|}{$\begin{array}{c}\text { High }(\mathrm{N}=92) \\
\mathrm{N}(\%)\end{array}$}} & \multirow{2}{*}{\multicolumn{2}{|c|}{$\begin{array}{c}\text { Total }(\mathrm{N}=231) \\
\mathrm{N}(\%)\end{array}$}} \\
\hline & & & & & & & & \\
\hline Smoking & 2 & $(4.3 \%)$ & 4 & $(4.3 \%)$ & 6 & $(6.5 \%)$ & 12 & $(5.2 \%)$ \\
\hline Alcohol drinking & 5 & $(10.6 \%)$ & 20 & $(21.4 \%)$ & 12 & $(12.5 \%)$ & 37 & $(16.0 \%)$ \\
\hline Overweight by body mass index & 17 & $(36.5 \%)$ & 27 & $(29.6 \%)$ & 23 & $(25.0 \%)$ & 67 & $(29.2 \%)$ \\
\hline Overweight by waist circumference & 12 & $(25.9 \%)$ & 25 & $(26.8 \%)$ & 15 & $(16.7 \%)$ & 52 & $(22.6 \%)$ \\
\hline Overweight by body fat $\%$ & 30 & $(63.5 \%)$ & 34 & $(36.6 \%)$ & 31 & (33.3\%) & 95 & $(41.1 \%)^{d}$ \\
\hline Physical inactivity & 4 & $(8.2 \%)$ & 5 & $(5.6 \%)$ & 4 & $(4.2 \%)$ & 13 & $(5.6 \%)$ \\
\hline High fasting glucose & 3 & $(5.9 \%)$ & 9 & $(9.6 \%)$ & 10 & $(11.1 \%)$ & 22 & $(9.5 \%)$ \\
\hline High Total cholesterol & 9 & $(18.4 \%)$ & 20 & $(21.4 \%)$ & 23 & $(25.0 \%)$ & 52 & $(22.5 \%)$ \\
\hline Low HDL- cholesterol & 4 & $(7.9 \%)$ & 10 & $(10.7 \%)$ & 8 & $(8.3 \%)$ & 22 & $(9.5 \%)$ \\
\hline High LDL- cholesterol & 11 & $(23.7 \%)$ & 20 & $(21.4 \%)$ & 23 & $(25.0 \%)$ & 54 & $(23.3 \%)$ \\
\hline High systolic blood pressure & 2 & $(5.3 \%)$ & 9 & $(10.0 \%)$ & 4 & $(4.5 \%)$ & 15 & $(6.5 \%)$ \\
\hline High diastolic blood pressure & 4 & $(8.9 \%)$ & 9 & $(10.0 \%)$ & 4 & $(4.3 \%)$ & 17 & $(7.5 \%)$ \\
\hline ST-Depression during exercise & 3 & $(6.4 \%)$ & 5 & $(5.4 \%)$ & 3 & $(3.3 \%)$ & 11 & $(4.8 \%)^{\mathbf{d}}$ \\
\hline Long QTC during exercise & 3 & $(6.4 \%)$ & 4 & $(4.3 \%)$ & 3 & $(3.3 \%)$ & 10 & $(4.3 \%)^{\mathbf{d}}$ \\
\hline
\end{tabular}

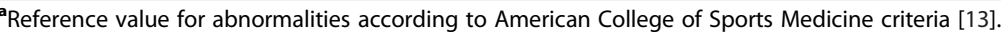

${ }^{\mathbf{b}}$ According to $\mathrm{VO}_{2 \max }$, the least fit $20 \%$ were classified as low fit, the next $40 \%$ as moderately fit, and the top $40 \%$ as high fit.

${ }^{\top} \mathrm{N}$ denotes the number of participants with the CVD risk factor within each CRF group, \% indicates the percentage of participants with the CVD risk factor within each CRF group.

${ }^{\mathbf{d}}$ Denotes significant difference $(P<0.01)$ in percentages among the three CRF groups.

PA was comprised of non-leisure-time PA, including work-related PA (23.6\%), transport-related PA (29.7\%), and household-related PA (19.0\%).

Overall, CVD risk profiles of the moderate and high CRF groups were more favorable than that of the low CRF group. There were significant differences in total weekly PA among the three CRF groups $(P<0.05)$, with total weekly PA being highest in the high CRF group and lowest in the low CRF group. Total weekly PA was significantly higher in the high CRF group than in the low CRF group $(P<0.05)$, with no significant difference between the moderate and low CRF group $(P>0.05)$. Higher CRF levels were also associated with significantly less BF\% $(P<0.05)$ and lower PWV $(P<0.05)$, which indicated less stiffness of the vasculature. There were significant differences in $\mathrm{BF} \%$ between the moderate and low CRF group $(P<0.05)$ and the high and low CRF group $(P<0.05)$. PWV was significantly lower in the high CRF group than in the low CRF group $(P<0.05)$. No significances were found in other variables $(P>0.05)$.

The chi-square test revealed significant differences in the proportions of abnormal $\mathrm{BF} \%$, ST segment depression, and long QTC interval across CRF groups $(P<0.05)$ (Table 2). The proportion of participants with overweight status, ST segment depression, and long QTC interval during cycle exercise testing were lowest in the high CRF group and highest in the low CRF group. No significances existed for those variables across CRF groups $(P>0.05)$.

After adjustment for a range of potential confounding factors including age, family history, income, education, smoking, diet, alcohol consumption and total PA, logistic regression indicated the odds ratio for having $\leq 1,2$, or $\geq 3$ CVD risk factors (Table 3 ). Odds ratios for having $\geq 3$ CVD risk factors in the low and moderate CRF groups were significantly higher compared with the high CRF group $(P<0.05)$. The likelihood of having $\geq 3 \mathrm{CVD}$ risk factors in the low CRF group was 2.09 times greater than women in the high CRF group. Also, the low CRF group had significant less probability of having $\leq 1$ CVD risk factors $(P<0.05)$. Table 3 also shows the that odds ratios of ST segment depression and long QTC interval during cycle exercise testing in the low and moderate CRF groups were significantly higher compared with the high CRF group $(P<0.05)$. This indicated the probability of myocardial ischemia in the high CRF group was significantly less than in the moderate and low CRF groups.

Figure 1 shows the trend of ST segment changes during exercise testing among different CRF groups. There were significant differences between the low and moderate CRF group $(P<0.05)$ and the low and high CRF group $(P<0.05)$. There were no significant differences between the high and moderate CRF group $(P>0.05)$. These data indicated the potential of myocardial ischemia 
Table 3 Odds ratio of number (N) of cardiovascular disease (CVD) risk factors and abnormal electrocardiogram (ECG) according to cardiorespiratory fitness level

\begin{tabular}{|c|c|c|c|c|c|c|c|}
\hline \multirow[t]{3}{*}{ Variable $^{a}$} & \multicolumn{7}{|c|}{ Fitness level $^{\mathbf{b}}$} \\
\hline & \multicolumn{3}{|c|}{ Low } & \multicolumn{3}{|c|}{ Moderate } & \multirow{2}{*}{$\begin{array}{c}\text { High }^{\mathrm{e}} \\
\text { (Reference) }\end{array}$} \\
\hline & & $\%$ C.I.) & P-value & & $\%$ C.I.) & P-value & \\
\hline \multicolumn{8}{|c|}{$\mathrm{N}$ of CVD risk factors ${ }^{\mathrm{c}}$} \\
\hline$\geq 3$ Risk factors & 2.09 & $(1.48-2.94)$ & $<0.01$ & 1.84 & $(1.29-2.62)$ & $<0.01$ & 1.00 \\
\hline 2 Risk factors & 1.60 & $(1.13-2.26)$ & $<0.01$ & 1.10 & $(0.76-1.60)$ & 0.61 & 1.00 \\
\hline$\leq 1$ Risk factors & 0.71 & $(0.51-0.99)$ & $<0.05$ & 0.79 & $(0.58-1.10)$ & 0.16 & 1.00 \\
\hline \multicolumn{8}{|c|}{ Abnormality in $E C G^{d}$} \\
\hline ST-Depression & 2.14 & $(1.52-3.00)$ & $<0.01$ & 1.63 & $(1.14-2.32)$ & $<0.01$ & 1.00 \\
\hline Long QTC & 2.06 & $(1.44-2.96)$ & $<0.01$ & 1.52 & $(1.04-2.23)$ & $<0.05$ & 1.00 \\
\hline
\end{tabular}

${ }^{a}$ Reference value for abnormalities according to ACSM instructions [13].

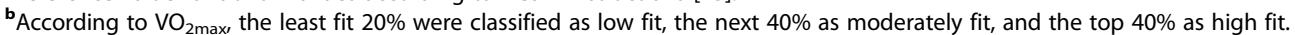

'Odds ratio (95\% confidence interval) of number of CVD risk factors related to overweight, hypertension, and dyslipidemia adjusted for age, family history, income, education, smoking, diet, alcohol consumption and total weekly physical activity.

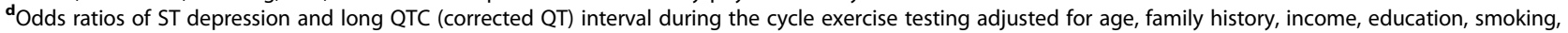
diet, alcohol consumption, total physical activity, and other CVD risk factors.

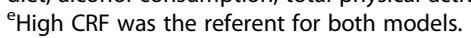

in both the high and moderate CRF groups was less than in the low CRF group. Figure 2 shows the pattern in QTC interval with significant differences between the low and moderate CRF group $(P<0.05)$ and the low and high CRF $\operatorname{group}(P<0.05)$. There were no significant differences between the high and moderate CRF group $(P>0.05)$.

\section{Discussion}

Beijing is the Capital of China with a population of approximate 16.85 million living in 11 urban districts. The burden of medical care for this large population has increased tremendously in recent years, especially for CVD $[16,17]$. The purpose of the current study was to examine the association between objectively measured CRF and several CVD risk factors in middle-aged women living in urban Beijing. To the best of our knowledge, this is the first study to explore this topic in a Chinese female population. The results of the present study demonstrated that CRF was significantly inversely associated with CVD risk in this population with both moderate and high levels of CRF being associated with reduced risk.

CRF is primarily a function of the heart's maximal ability to pump blood and the ability of skeletal muscle to extract and use oxygen. It is a more objective measure reflecting the PA level and cardiovascular function than self-reported PA which is prone to bias [15]. CRF is influenced by both genetic and environmental factors. Environment, such as the frequency, intensity and duration of daily PA, has a significant effect on CRF, and appears to account for more of the variation in CRF than do genetic factors.

We observed that CRF was strongly and inversely associated with $\mathrm{BF} \%$. As a more precise variable, $\mathrm{BF} \%$ measured by BIA indicated an association between fatness and CRF, while BMI failed to exclude the confounding effect of lean body mass. Regular PA has been shown to reduce the risks for obesity and metabolic disease at all

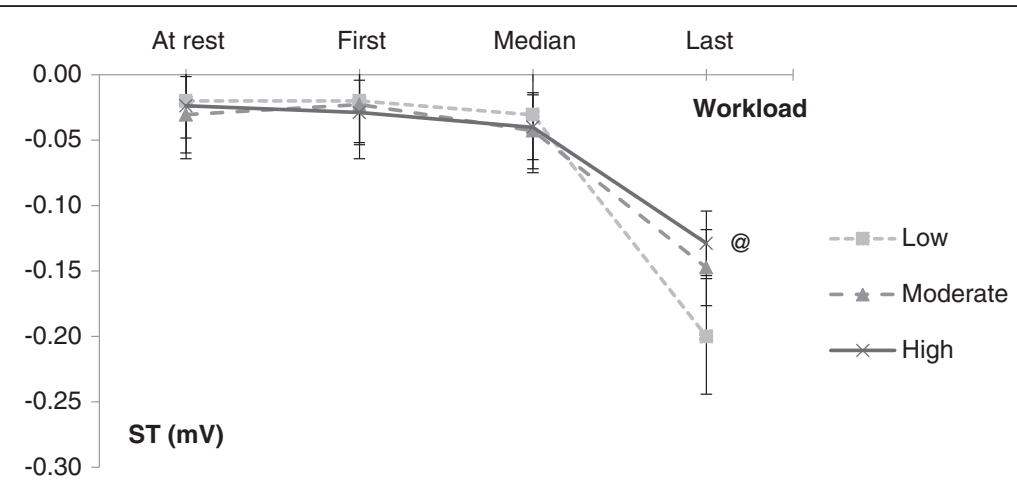

Figure 1 ST Segment Change during Exercise Test. The average values were recorded at rest, the first workload, the median workload and the last workload phase. @ denotes significant difference $(P<0.05)$ in the trend of change among the three CRF groups. 


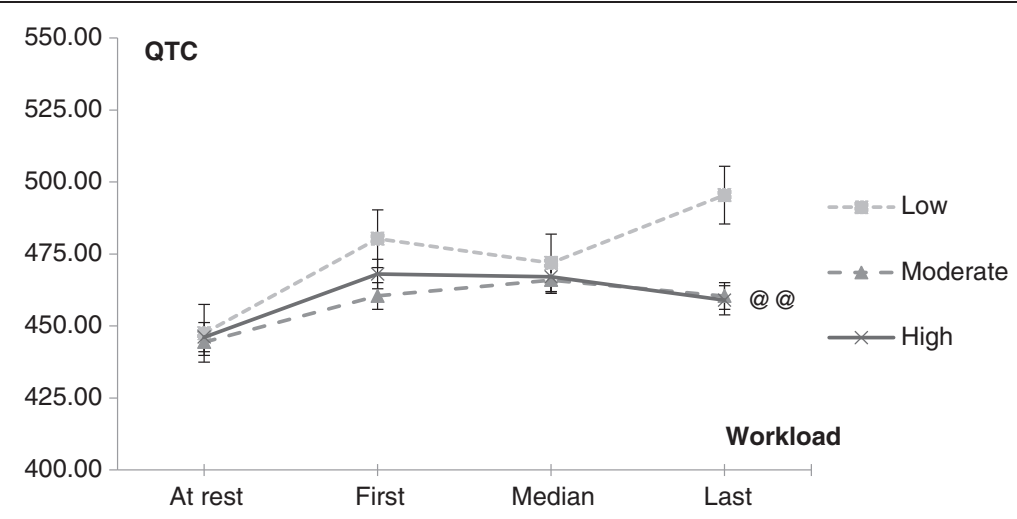

Figure 2 QTC interval Change during Exercise Test. The average values were recorded at rest, the first workload, the median workload and the last workload phase. @@ denotes significant difference $(P<0.01)$ in the trend of change among the three CRF groups.

ages. Recent studies $[4,18-20]$ support the finding that higher CRF is related to lower risks of obesity for both men and women. For example, Irwin et al. [21] reported higher levels CRF predicted less body weight and lower $\mathrm{BF} \%$. One study conducted in Hong Kong [22] also showed a significant inverse association between BF\% and CRF in women aged 55-94 years. Similar results from Wong et al. [23] demonstrated body fat mass and lean body mass were independently associated with $\mathrm{VO}_{2 \max }$ in Chinese adults. The CRF level measured in our study was also consistent with results for adult women aged 40-49 years old who performed cycle exercise tests in these two studies [22,23].

CRF was also significantly negatively associated with PWV, which is a valid and reliable measurement of arterial stiffness. PWV indicates the general burden of atherosclerotic disease and subclinical damage from multiple risk factors over time, such as the effects of aging, smoking, and lipid metabolism [24]. In alignment with our results, recent studies have also discovered that CRF is associated with arterial stiffness. Boreham et al. [25] reported CRF was inversely related to PWV in young adults, and the relationship was independent of other CVD risk factors and daily PA levels. Gando et al. [26] reported higher CRF was associated with lower BP and arterial stiffness in older women. One possible reason for the relationship is that higher CRF minimizes age-related structural changes in the arterial wall related to an elevated overall content of elastin and a reduced calcium content [27]. Another possibility is higher CRF may act to maintain endotheliumdependent vasodilation [28].

We did not observe significant differences in FBG, TC, HDL-C, LDL-C, SBP, and DBP among the three CRF groups. This may be partially due to the inclusion of participants asymptomatic of CVD. Also, participants might suffer from diverse CVD risk factors which made it harder to detect a difference in the general CVD risk profile across participants. Thus, we used ACSM's risk factor stratification [13] to summarize and evaluate the CVD risk within the sample. We used overweight, hypertension, and dyslipidemia as the main CVD risk factors as previous research and theories $[5,29,30]$ support the relationship between these factors and CRF. We also controlled for age, family history, smoking, total weekly PA and other factors to clarify the relationship. The results of revealed women with high to moderate CRF were significantly less likely to have $\geq 3$ CVD risk factors, and more likely to have $\leq 1$ CVD risk factors. Therefore, CRF was inversely associated with the risk of CVD.

Furthermore, the results (Table 3, Figures 1 and 2) from the ECG during exercise testing disclosing greater myocardial ischemia in women with the lowest CRF also supports the association mentioned above. Some CVD risk factors might fail to provide prognostic information of CVD among an asymptomatic population, while results from exercise testing can help guide decisions regarding CVD risk evaluation. It is suggested that exercise testing be recommended for adults with the presence of at least one conventional CVD risk factor [13], although the prognostic importance of exercise-induced ST segment depression and long QTC interval still needs clarification. Nonetheless, similar to our findings, other studies have also observed an association between CRF and abnormal ECG during exercise testing. Lakka et al. [31] reported higher levels of both leisure-time PA and CRF had a strong, graded, inverse association with the risk of ST segment depression during exercise and acute myocardial infarction during follow-up. Church et al. [32] also noticed a significant relationship among CRF, abnormal exercise ECG, and future CVD mortality. Our study included ECG during exercise testing as an important aspect in the evaluation of CVD risk. This is the first report of the significant relationship between CRF and odds ratios of ST segment depression and long QTC interval in any Chinese female population. 
The results regarding the relation between CRF and CVD risk factors were in agreement with the conclusions of a series of reports with non-Chinese women $[5,18,30,33,34]$. A cross-sectional study from Kokkinos and colleagues [30] showed women in the lowest CRF category had a less favorable CVD risk profile than those in moderate and high CRF categories. Haddock et al. [5] reported higher CRF levels were significantly associated with lower TC, TG, and higher HDL in women regardless of their hormonal status. Longitudinal studies have also confirmed these results. Blair et al. [15] reported moderate CRF had a protective effect against CVD risk and reduced the risk of premature mortality. Kodama et al. [10] indicated increased CRF was associated with lower risk of all-cause mortality and incidence of CVD. However, most studies have been based on white and high-income populations in western countries, mainly the United States. To date, there is no similar report focused on a Chinese population.

Interestingly, our results also indicated total weekly PA was much higher than the average level demonstrated by women in western developed countries (i.e., more than five times the recommended dose in the American PA Guidelines) [33]. Our PA findings approximate data $\left(4672 \pm 1692 \mathrm{MET} \cdot \mathrm{min} \cdot\right.$ week $\left.^{-1}\right)$ also collected by IPAQ in the Guangzhou Biobank Cohort Study [35]. Additionally, the time spent in leisure-time PA among the current study's middle-aged women was relatively low (27.7\%) while the transport-related PA was relatively high (29.7\%) compared to that observed in western developed countries [33]. The proportion of time spent in these two types of activities is similar to a previous study focused on commuting, leisure-time PA, and CVD risk factors in China [3]. The reason for the higher levels of transport-related PA is that China is the largest bicycleusing country in the world, and most Chinese living in urban settings use a bicycle, utilize public transportation, or walk to and from work, shopping or school [35]. Also, the retirement age for Chinese women is between 50-55 years old, depending on the type of job. Most of our participants were full-time workers with additional responsibilities to take care of family members at home. Therefore, their total weekly PA is high. Although leisure-time PA has been thought to be more efficient in improving health-related factors, recent research $[11,33]$ has shown total PA is the key variable associated with a more favorable CVD risk profile.

This study is the first to document the total PA by IPAQ and directly-measured CRF levels in Chinese middle-aged women. It is also the first study to report the association between CRF and CVD risk in this unique female population. Moreover, we have documented an inverse association between CRF and fatness, and also added various CVD risk factors in the evaluation, such as PWV at rest and ECG during exercise testing, providing a more comprehensive picture of the CVD risk profile.

The current study also had some limitations. First, it was a cross-sectional study, and it does not disclose a causal relationship between CRF and CVD risk. Second, the sample was restricted to one age group and geographic area. Further studies are needed to generalize the conclusions to a larger population with different ages and geographic regions. Also, despite the common use of bicycles among these women, the cycle exercise test might underscore the CRF of these women by $5-10 \%$ compared with a treadmill test. Nonetheless, our results add value to the existing data highlighting the association between CRF and CVD risk profile with implications toward the prevention of CVD in Chinese women.

\section{Conclusions}

The total weekly PA of this population was high, and mainly consisted of non-leisure-time PA. Moderate and high levels of CRF measured by a cycle exercise test were significantly related to the CVD risk profile in 40-49 year old Chinese women living in the urban district of Beijing. It seems reasonable to suggest a stronger emphasis be placed on increasing the CRF level of this population via regular PA, especially for those who are unfit. Further studies need to confirm the causal relationship between CRF and CVD risk for Chinese and Asian female populations.

\section{Competing interests}

The authors declare that they have no competing financial interests exist.

\section{Authors' contributions}

WZ, JC and SH conceived the study, completed most of the statistical analyses, and drafted the manuscript. MX and HS carried out the design and implementation of the study. YS helped to interpret the data and draft the manuscript. All authors have read and approved the final manuscript.

\section{Acknowledgments}

This research was supported by National Key Technology R\&D Program of Ministry of Science and Technology in China (2006BAK33B02) and the Health Promotion Research Center in Beijing Sport University. We appreciate the participants and their families who devoted their time to the study. We are also grateful to all of the members in our study group in Beijing Sport University and Arizona State University.

\section{Author details}

${ }^{1}$ School of Nutrition and Health Promotion, Arizona State University, Phoenix, AZ 85004, USA. ${ }^{2}$ Key Laboratory of Exercise and Health Science of the Ministry of Education, Shanghai University of Sport, Shanghai 200438, P. R. China. ${ }^{3}$ Sport Science College, Beijing Sport University, Beijing 100084, P. R. China. ${ }^{4}$ Sport Biochemistry Program, Sport Science College, Beijing Sport University, No.48 Xinxi Road, Beijing, Haidian District 100084, P. R. China.

Received: 19 February 2014 Accepted: 25 April 2014

Published: 1 May 2014

\section{References}

1. He J, Gu D, Wu X, Reynolds K, Duan X, Yao C, Wang J, Chen C, Chen J, Wildman RP: Major causes of death among men and women in China. N Engl J Med 2005, 353(11):1124-1134. 
2. Gu D, He J, Duan X, Reynolds K, Wu X, Chen J, Huang G, Chen C, Whelton PK Body weight and mortality among men and women in China. JAMA 2006, 295(7):776-783.

3. Hu G, Pekkarinen $H$, Hanninen $\mathrm{O}, \mathrm{Yu} Z$ Z, Guo Z, Tian H: Commuting, leisure-time physical activity, and cardiovascular risk factors in China. Med Sci Sports Exerc 2002, 34(2):234-238.

4. Lee CD, Blair SN, Jackson AS: Cardiorespiratory fitness, body composition, and all-cause and cardiovascular disease mortality in men. Am J Clin Nutr 1999, 69(3):373-380.

5. Haddock BL, Hopp HP, Mason JJ, Blix G, Blair SN: Cardiorespiratory fitness and cardiovascular disease risk factors in postmenopausal women. Med Sci Sports Exerc 1998, 30(6):893-898

6. Hu G, Tuomilehto J, Silventoinen K, Barengo N, Jousilahti P: Joint effects of physical activity, body mass index, waist circumference and waist-to-hip ratio with the risk of cardiovascular disease among middle-aged Finnish men and women. Eur Heart J 2004, 25(24):2212-2219.

7. Church TS, Earnest CP, Skinner JS, Blair SN: Effects of different doses of physical activity on cardiorespiratory fitness among sedentary, overweight or obese postmenopausal women with elevated blood pressure. JAMA 2007, 297(19):2081-2091.

8. Anderssen SA, Cooper AR, Riddoch C, Sardinha LB, Harro M, Brage S, Andersen LB: Low cardiorespiratory fitness is a strong predictor for clustering of cardiovascular disease risk factors in children independent of country, age and sex. Eur J Cardiol Prev Rehabil 2007, 14(4):526-531.

9. Lee DC, Sui X, Ortega F, Kim Y, Church T, Winett R, Ekelund U, Katzmarzyk P, Blair SN: Comparisons of leisure-time physical activity and cardiorespiratory fitness as predictors of all-cause mortality in men and women. $\mathrm{Br} J$ Sports Med 2011, 45(6):504-510.

10. Kodama S, Saito K, Tanaka S, Maki M, Yachi Y, Asumi M, Sugawara A, Totsuka K, Shimano H, Ohashi Y: Cardiorespiratory fitness as a quantitative predictor of all-cause mortality and cardiovascular events in healthy men and women. JAMA 2009, 301(19):2024-2035.

11. Matthews CE, Jurj AL, Shu XO, Li H, Yang G, Li Q, Gao Y, Zheng W: Influence of exercise, walking, cycling, and overall nonexercise physical activity on mortality in Chinese women. Am J Epidemiol 2007, 165(12):1343-1350.

12. Hagstromer M, Oja P, Sjostrom M: The International Physical Activity Questionnaire (IPAQ): a study of concurrent and construct validity. Public Health Nutr 2006, 9(6):755-762.

13. Thompson WR, Gordon NF, Pescatello LS: ACSM's guidelines for exercise testing and prescription. 8th edition. Edited by Thompson WR, Gordon NF, Pescatello LS. Philadelphia: Wolters Kluwer Lippincott Williams \& Wilkins; 2010:35-96

14. Meyer T, Georg T, Becker C, Kindermann W: Reliability of gas exchange measurements from two different spiroergometry systems. Int J Sports Med 2001, 22(8):593-597.

15. Blair SN, Kampert JB, Kohl HW III, Barlow CE, Macera CA, Paffenbarger RS Jr Gibbons LW: Influences of cardiorespiratory fitness and other precursors on cardiovascular disease and all-cause mortality in men and women. JAMA 1996, 276(3):205-210.

16. Truelsen $T$, Mähönen M, Tolonen $H$, Asplund $K$, Bonita R, Vanuzzo D: Trends in stroke and coronary heart disease in the WHO MONICA Project. Stroke 2003, 34(6):1346-1352.

17. Critchley J, Liu J, Zhao D, Wei W, Capewell S: Explaining the increase in coronary heart disease mortality in Beijing between 1984 and 1999. Circulation 2004, 110(10):1236-1244.

18. Evans EM, Racette SB: Menopause and risk for obesity: how important is physical activity? J Womens Health (Larchmt) 2006, 15(2):211-213.

19. Church TS, Kuk JL, Ross R, Priest EL, Biltoff E, Blair SN: Association of cardiorespiratory fitness, body mass index, and waist circumference to nonalcoholic fatty liver disease. Gastroenterology 2006, 130(7):2023-2030.

20. Mattila VM, Tallroth K, Marttinen M, Pihlajamäki H: Body composition by DEXA and its association with physical fitness in 140 conscripts. Med Sci Sports Exerc 2007, 39(12):2242-2247.

21. Irwin ML, Yasui Y, Ulrich CM, Bowen D, Rudolph RE, Schwartz RS, Yukawa M, Aiello E, Potter JD, McTiernan A: Effect of exercise on total and intra-abdominal body fat in postmenopausal women. JAMA 2003, 289(3):323-330.

22. Yu R, Yau F, Ho S, Woo J: Cardiorespiratory fitness and its association with body composition and physical activity in Hong Kong Chinese women aged from 55 to 94 years. Maturitas 2011, 69(4):348-353.
23. Wong SY, Chan FW, Lee CK, Li M, Yeung F, Lum CC, Choy DT, Woo J: Maximum oxygen uptake and body composition of healthy Hong Kong Chinese adult men and women aged 20-64 years. J Sports Sci 2008, 26(3):295-302

24. Cruickshank JK, Rezailashkajani M, Goudot G: Arterial stiffness, fatness, and physical fitness ready for intervention in childhood and across the life course? Hypertension 2009, 53(4):602-604.

25. Boreham CA, Ferreira I, Twisk JW, Gallagher AM, Savage MJ, Murray LJ: Cardiorespiratory fitness, physical activity, and arterial stiffness: the Northern Ireland Young Hearts Project. Hypertension 2004, 44(5):721-726.

26. Gando Y, Kawano H, Yamamoto K, Sanada K, Tanimoto M, Oh T, Ohmori Y Miyatani M, Usui C, Takahashi E: Age and cardiorespiratory fitness are associated with arterial stiffening and left ventricular remodelling. J Hum Hypertens 2009, 24(3):197-206.

27. Lakatta EG, Levy D: Arterial and cardiac aging: major shareholders in cardiovascular disease enterprises part l: aging arteries: a "set up" for vascular disease. Circulation 2003, 107(1):139-146.

28. Hambrecht R, Wolf A, Gielen S, Linke A, Hofer J, Erbs S, Schoene N, Schuler G: Effect of exercise on coronary endothelial function in patients with coronary artery disease. N Engl J Med 2000, 342(7):454-460.

29. LaMonte MJ, Eisenman PA, Adams TD, Shultz BB, Ainsworth BE, Yanowitz FG: Cardiorespiratory fitness and coronary heart disease risk factors the LDS Hospital Fitness Institute cohort. Circulation 2000, 102(14):1623-1628.

30. Kokkinos PF, Holland JC, Pittaras AE, Narayan P, Dotson CO, Papademetriou V: Cardiorespiratory fitness and coronary heart disease risk factor association in women. J Am Coll Cardiol 1995, 26(2):358-364.

31. Lakka TA, Venalainen JM, Rauramaa R, Salonen R, Tuomilehto J, Salonen JT: Relation of leisure-time physical activity and cardiorespiratory fitness to the risk of acute myocardial infarction in men. N Engl J Med 1994 330(22):1549-1554.

32. Church TS, LaMonte MJ, Barlow CE, Blair SN: Cardiorespiratory fitness and body mass index as predictors of cardiovascular disease mortality among men with diabetes. Arch Intern Med 2005, 165(18):2114.

33. Haskell WL, Lee I, Pate RR, Powell KE, Blair SN, Franklin BA, Macera CA, Heath GW, Thompson PD, Bauman A: Physical activity and public health: updated recommendation for adults from the American College of Sports Medicine and the American Heart Association. Med Sci Sports Exerc 2007, 39(8):1423

34. Sui X, LaMonte MJ, Laditka JN, Hardin JW, Chase N, Hooker SP, Blair SN: Cardiorespiratory fitness and adiposity as mortality predictors in older adults. JAMA 2007, 298(21):2507-2516.

35. Deng HB, Macfarlane DJ, Thomas GN, Lao XQ, Jiang CQ, Cheng KK, Lam TH: Reliability and validity of the IPAQ-Chinese: the Guangzhou Biobank Cohort study. Med Sci Sports Exerc 2008, 40(2):303-307.

doi:10.1186/1472-6874-14-62

Cite this article as: Zhu et al:: Associations of cardiorespiratory fitness with cardiovascular disease risk factors in middle-aged Chinese women: a cross-sectional study. BMC Women's Health 2014 14:62.

\section{Submit your next manuscript to BioMed Central and take full advantage of:}

- Convenient online submission

- Thorough peer review

- No space constraints or color figure charges

- Immediate publication on acceptance

- Inclusion in PubMed, CAS, Scopus and Google Scholar

- Research which is freely available for redistribution 